\title{
Critical earthquake response of elastic-plastic structures under near-fault ground motions (Part 2: Forward-directivity input)
}

\author{
Kotaro Kojima and Izuru Takewaki * \\ Department of Architecture and Architectural Engineering, Graduate School of Engineering, Kyoto University, Kyoto, Japan
}

OPEN ACCESS

Edited by:

Nikos D. Lagaros,

National Technical University of

Athens, Greece

Reviewed by:

Johnny Ho,

The University of Queensland,

Australia

Sameh Samir F. Mehanny,

Cairo University, Egypt

*Correspondence:

Izuru Takewaki,

Department of Architecture and Architectural Engineering, Graduate

School of Engineering, Kyoto University, Kyotodaigaku-Katsura, Nishikyo, Kyoto 615-8540, Japan

takewaki@archi.kyoto-u.ac.jp

Specialty section: This article was submitted to Earthquake Engineering, a section of the journal Frontiers in Built Environment

Received: 23 June 2015 Accepted: 16 July 2015 Published: 03 August 2015

Citation:

Kojima K and Takewaki I (2015) Critical earthquake response of elastic-plastic structures under near-fault ground motions (Part 2:

Forward-directivity input).

Front. Built Environ. 1:13.

doi: 10.3389/fbuil.2015.00013
The triple impulse input is used as a simplified version of the forward-directivity near-fault ground motion and a closed-form solution of the elastic-plastic response of a structure by this triple input is obtained. It is noteworthy that only the free-vibration appears under such triple impulse input. An almost critical excitation is defined and its response is derived. The energy approach plays an important role in the derivation of the closed-form solution of a complicated elastic-plastic response. It is shown that the maximum inelastic deformation can occur after the second impulse or the third impulse depending on the input level. The validity and accuracy of the proposed theory are discussed through the comparison with the response analysis result to the corresponding three wavelets of sinusoidal waves as a representative of the forward-directivity near-fault ground motion.

Keywords: earthquake response, critical response, elastic-plastic response, ductility factor, near-fault ground motion, forward-directivity input, triple impulse

\section{Introduction}

The near-fault ground motions have been investigated from various viewpoints (Bertero et al., 1978; Hall et al., 1995; Sasani and Bertero, 2000; Alavi and Krawinkler, 2004; Mavroeidis et al., 2004; Kalkan and Kunnath, 2006, 2007; Xu et al., 2007; Rupakhety and Sigbjörnsson, 2011; Yamamoto et al., 2011; Khaloo et al., 2015; Kojima and Takewaki, 2015b; Vafaei and Eskandari, 2015). Those ground motions are characterized by the well-known phenomena called fling-step and forwarddirectivity (Mavroeidis and Papageorgiou, 2003; Bray and Rodriguez-Marek, 2004; Kalkan and Kunnath, 2006; Mukhopadhyay and Gupta, 2013a,b; Zhai et al., 2013; Hayden et al., 2014; Yang and Zhou, 2014; Kojima and Takewaki, 2015b).

As pointed out in the previous paper (Kojima and Takewaki, 2015b), the fling-step input is a fault-parallel input and the forward-directivity input are a fault-normal input. Those ground motions have been characterized by two or three wavelets and it is recognized that the forward-directivity input has larger effects on structures in general. Recently, some important research works have been conducted. Mavroeidis and Papageorgiou (2003) summarized the characteristics of this class of ground motions in detail and proposed some simple wavelet models (for example, Gabor wavelet and Berlage wavelet). Xu et al. (2007) employed the Berlage wavelet and applied it to the performance evaluation of passive energy dissipation systems. Takewaki and Tsujimoto (2011) used the Xu's model and proposed a method for scaling ground motions from the viewpoints of drift and input energy demand. Takewaki et al. (2012) employed a sinusoidal wave for pulse-type waves. Kojima and Takewaki (2015b) introduced a simplified input model called "double impulse" (Kojima et al., 2015a) 
and derived a closed-form solution of the critical elastic-plastic deformation of a single-degree-of-freedom (SDOF) model to the double impulse input. They clarified that (i) a closed-form solution of the critical elastic-plastic deformation can be derived based on a simple energy approach and (ii) the double impulse can be a good substitute of the fling-step input (one-cycle sinusoidal input) under the equivalence assumption of the maximum Fourier amplitude of accelerations. In this paper, the approach by Kojima and Takewaki (2015b) is extended to the forwarddirectivity input and the intrinsic response characteristics by the forward-directivity are captured.

Most of the previous works on the near-fault ground motions deal with the elastic response because the number of parameters (e.g., duration and amplitude of pulse, ratio of pulse frequency to structure natural frequency, change of equivalent natural frequency for the increased input level) to be considered is tremendous and the computation of elastic-plastic response itself is quite complicated.

In order to tackle such important but complicated problem, a simple input as the double impulse has been employed as a substitute of the fling-step near-fault ground motion in the previous paper (Kojima and Takewaki, 2015b) and a closed-form solution of the critical elastic-plastic response of a structure by this double impulse has been derived. Following the previous paper, the approach is extended to the forward-directivity input. It is shown that, since only the free-vibration appears under such triple impulse input, the energy approach plays an important role in the derivation of the closed-form solution of a complicated elastic-plastic response. An almost critical excitation is defined and its response is derived. It is also shown that the maximum inelastic deformation can occur either after the second impulse or after the third impulse depending on the input level. The validity and accuracy of the proposed theory are investigated through the comparison with the response analysis result to the corresponding three wavelets of sinusoidal input as a representative of the forward-directivity near-fault ground motion. The amplitude of the triple impulse is modulated so that its maximum Fourier amplitude coincides with that of the corresponding three wavelets of sinusoidal input.

The closed-form solutions of the elastic-plastic response have been obtained so far only for the steady-state response to an extremely simple sinusoidal input (Caughey, 1960; Liu, 2000). In the previous paper (Kojima and Takewaki, 2015b) and this paper, the following motivation is posed. If a near-fault ground motion can be represented by double impulse or triple impulse, the critical elastic-plastic response (continuation of free-vibrations) can be derived by an energy approach. The input of impulse is expressed by the instantaneous change of velocity of the structural mass. The restriction of the response to an almost critical one, which may be interesting in the design stage for safety, enables a unique solution of such complicated elastic-plastic responses.

While the resonant equivalent frequency has to be computed for a specified input level by changing the excitation frequency in a parametric manner in dealing with a sinusoidal input (Caughey, 1960; Liu, 2000), no iteration is required in the proposed method for the triple impulse. This is because the resonant equivalent frequency (resonance can be proved by using energy investigation) can be obtained directly without the repetitive procedure (the timing of the second impulse can be characterized as the time with zero restoring force). In the triple impulse, the analysis can be conducted without the input frequency (timing of impulses) before the second impulse. The criticality is defined only for the response before the third impulse and it is shown that this restriction is a reasonable condition for safety evaluation of structures. The maximum elastic-plastic response after impulse can be obtained by equating the initial kinetic energy computed by the initial velocity to the sum of hysteretic and elastic strain energies. It should be pointed out that only critical response (upper bound) is captured by the proposed method and the critical resonant frequency can be obtained automatically for the increasing input level of the triple impulse.

The significance of using a one-cycle sinusoidal wave and three wavelets of sinusoidal wave as substitutes of fling-step and forward-directivity ground motion inputs have been explained by many researchers (Mavroeidis and Papageorgiou, 2003; Kalkan and Kunnath, 2006) and comparison with recorded ground motions has been conducted. On the other hand, the merit of the present paper is to derive a closed-form solution for even elastic-plastic responses under the critical input, which will reduce the computational load drastically and enhance the safety level of structures under such near-fault ground motions.

\section{Triple Impulse Input}

As pointed out in the previous paper (Kojima and Takewaki, 2015b), it is well accepted that the fling-step input (fault-parallel) of the near-fault ground motion can be represented by a one-cycle sinusoidal wave and the forward-directivity input (fault-normal) of the near-fault ground motion can be expressed by three wavelets of sinusoidal input (see Figure 1). In the previous paper and this paper, it is intended to simplify these typical near-fault ground motions by double impulse (Kojima et al., 2015a) or triple impulse. This is because the double impulse and triple impulse have a simple characteristic and a straightforward expression of response can be expected even for elastic-plastic responses based on a simple energy approach to free vibrations. Furthermore, the double impulse and triple impulse enable us to describe directly the critical timing of impulses (resonant frequency), which is not possible for the sinusoidal and other inputs without a repetitive procedure.

Consider a ground motion acceleration $\ddot{u}_{\mathrm{g}}(t)$ as triple impulse, as shown in Figure 1B, expressed by

$$
\ddot{u}_{g}(t)=0.5 V \delta(t)-V \delta\left(t-t_{0}\right)+0.5 V \delta\left(t-2 t_{0}\right)
$$

where $0.5 \mathrm{~V}$ is the given initial velocity and $t_{0}$ is the time interval among three impulses. The comparison with the corresponding three wavelets of sinusoidal waves as a representative of the forward-directivity input of the near-fault ground motion (Mavroeidis and Papageorgiou, 2003; Kalkan and Kunnath, 2006) is also plotted in Figure 1B. The corresponding velocity and displacement of such triple impulse and three wavelets of sinusoidal waves are plotted in Figure 1B. The Fourier transform of $\ddot{u}_{\mathrm{g}}(t)$ of the triple impulse input can be derived as 


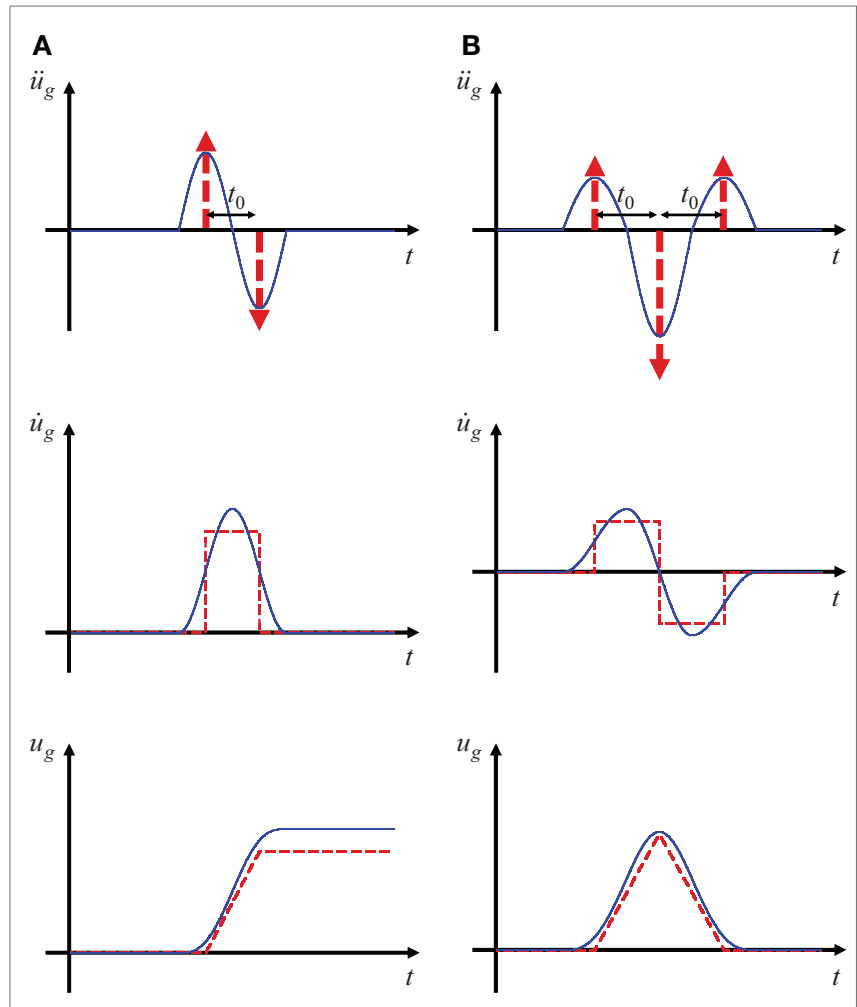

FIGURE 1 | (A) Fling-step input and double impulse, (B) Forward-directivity input and triple impulse (Kojima and Takewaki, 2015b).

$$
\begin{aligned}
\ddot{U}_{\mathrm{g}}(\omega) & =\int_{-\infty}^{\infty}\left\{0.5 V \delta(t)-V \delta\left(t-t_{0}\right)+0.5 V \delta\left(t-2 t_{0}\right)\right\} e^{-\mathrm{i} \omega t} d t \\
& =\int_{-\infty}^{\infty}\left\{\begin{array}{c}
0.5 V \delta(t) e^{-\mathrm{i} \omega t}-V \delta\left(t-t_{0}\right) e^{-\mathrm{i} \omega t_{0}} e^{-\mathrm{i} \omega\left(t-t_{0}\right)} \\
+0.5 V \delta\left(t-2 t_{0}\right) e^{-\mathrm{i} \omega 2 t_{0}} e^{-\mathrm{i} \omega\left(t-2 t_{0}\right)}
\end{array}\right\} d t \\
& =V\left(0.5-e^{-\mathrm{i} \omega t_{0}}+0.5 e^{-\mathrm{i} \omega 2 t_{0}}\right)
\end{aligned}
$$

\section{SDOF System}

Consider an undamped elastic-perfectly plastic SDOF system of mass $m$ and stiffness $k$. The yield deformation and the yield force are denoted by $d_{\mathrm{y}}$ and $f_{\mathrm{y}}$. Let $\omega_{1}=\sqrt{k / m}, u$ and $f$ denote the undamped natural circular frequency, the displacement (deformation) of the mass relative to the ground and the restoring force of the model, respectively. The time derivative is denoted by an over-dot.

\section{Maximum Elastic-Plastic Deformation of SDOF System Subjected to Triple Impulse}

The elastic-plastic response to the triple impulse can be described by the continuation of free-vibrations. The maximum deformation after the first impulse is denoted by $u_{\max }$, that after the second impulse is expressed by $u_{\max 2}$ and that after the third impulse is described by $u_{\max 3}$ as shown in Figure 2 . The input of each impulse is expressed by the instantaneous change of velocity of the structural mass. Such response can be derived by the combination of a simple energy approach and the solution of differential equations (equations of motion). The kinetic energy given at the initial stage (the time of the first impulse), that at the time of the second impulse, and the kinetic energy plus the elastic strain energy at the time of the third impulse are transformed into the sum of the hysteretic energy and the elastic strain energy corresponding to the yield deformation. Using this rule and incorporating the information from the equations of motion, the maximum deformation can be obtained in a simple manner. It should be noted that, while a simple and clear concept of critical input was defined in the case of double impulse (Kojima and Takewaki, 2015b), the criticality can be used only before the third impulse in the present triple impulse. This is because the timing of the third impulse, determined already for the first and second impulses, decreases the maximum deformation $u_{\max 2}$ after the second impulse and may increase the maximum deformation $u_{\max 3}$ after the third impulse. However, it is shown that this treatment of setting of timing provides the true criticality in an input level of practical interest.

It should also be emphasized that, while the resonant equivalent frequency has to be computed for a specified input level by changing the excitation frequency in a parametric or mathematical programing manner in dealing with the sinusoidal input (Caughey, 1960; Liu, 2000; Moustafa et al., 2010), no iteration is required in the proposed method for the triple impulse. This is because the resonant equivalent frequency (resonance can be proved by using energy investigation: see Proof of Critical Timing in Appendix) can be obtained directly without the repetitive procedure (the timing of the second impulse can be characterized as the time with zero restoring force). It should be noted again that the resonance is defined before the third impulse.

Only critical response (upper bound) is captured by the proposed method and the critical resonant frequency can be obtained automatically for the increasing input level of the triple impulse. One of the original points in this paper is the introduction of the concept of "critical excitation" in the elastic-plastic response (Drenick, 1970; Abbas and Manohar, 2002; Takewaki, 2004, 2007; Moustafa et al., 2010; Kojima and Takewaki, 2015b). Once the frequency and amplitude of the critical triple impulse are computed, the corresponding three wavelets of sinusoidal waves as a representative of the forward-directivity motion can be identified.

Let us explain the evaluation method of $u_{\max 1}, u_{\max 2}$, and $u_{\max 3}$. The plastic deformation after the first impulse is expressed by $u_{\mathrm{p} 1}$, that after the second impulse is described by $u_{\mathrm{p} 2}$, and that after the third impulse is denoted by $u_{\mathrm{p} 3}$. There are four cases to be considered depending on the yielding stage.

Case 1: elastic response during all response stages $\left(u_{\max 3}\right.$ is the largest).

Case 2: yielding after the third impulse ( $u_{\max 3}$ is the largest).

Case 3: yielding after the second impulse $\left(u_{\max 2}\right.$ or $u_{\max 3}$ is the largest).

1: the timing of the third impulse is in the unloading stage.

2: the timing of the third impulse is in the yielding (loading) stage.

Case 4: yielding after the first impulse ( $u_{\max 2}$ is the largest). 

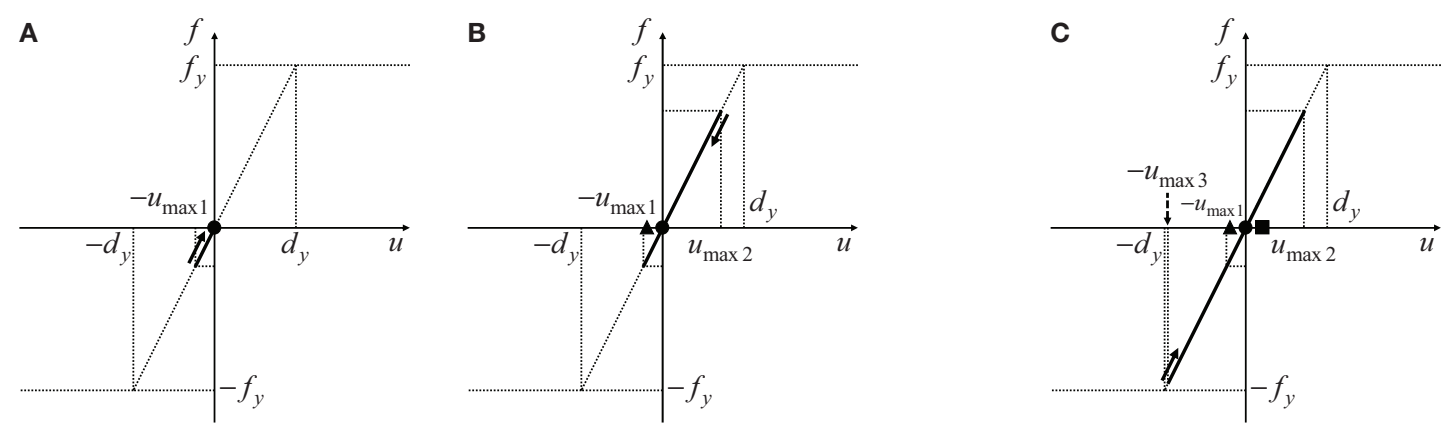

CASE 1
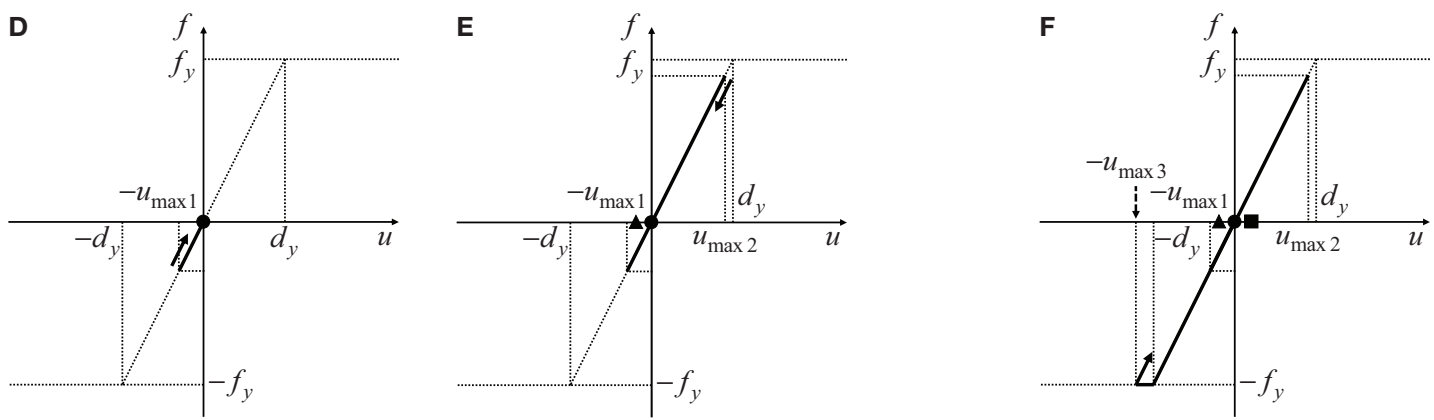

CASE 2
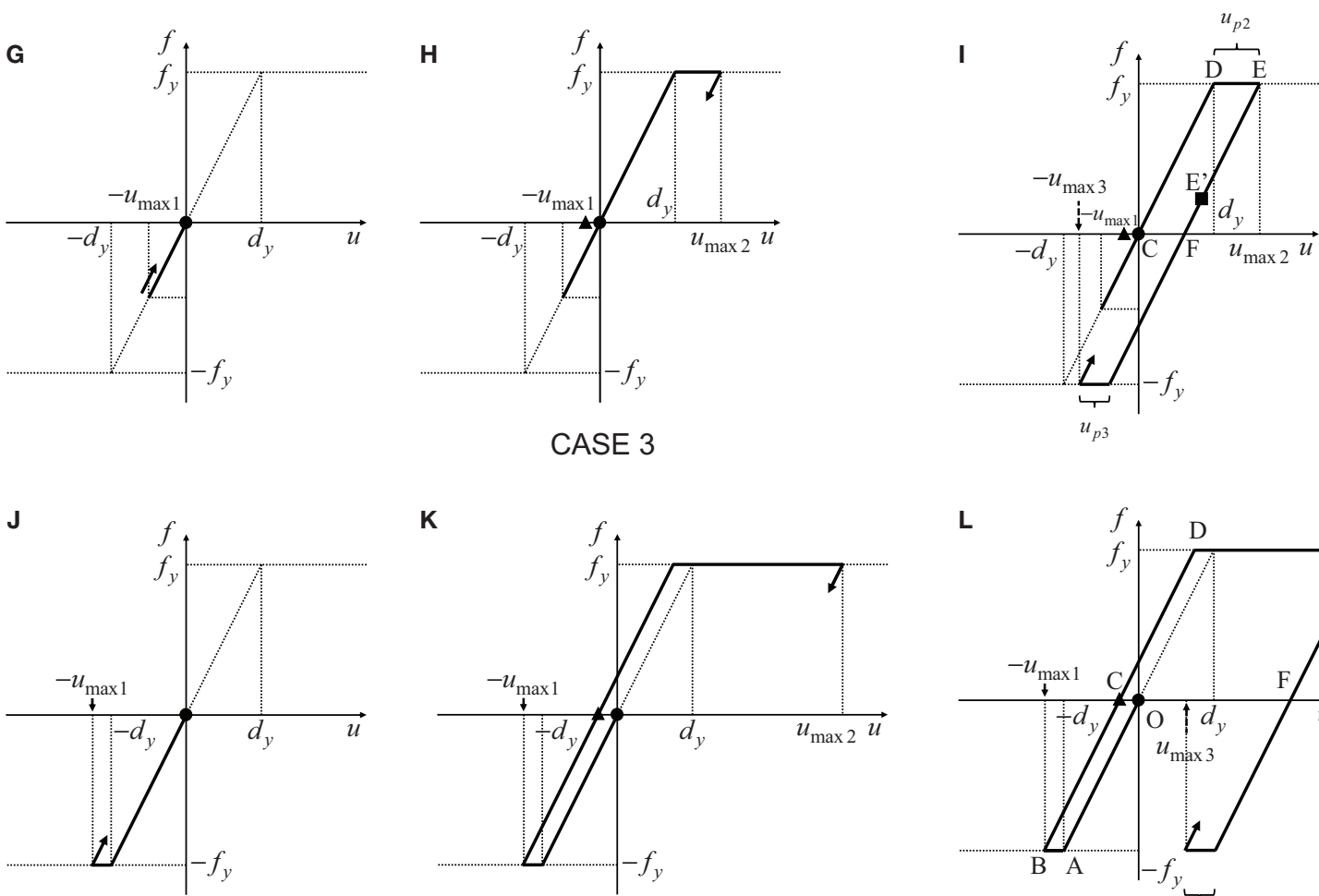

\section{CASE 4}

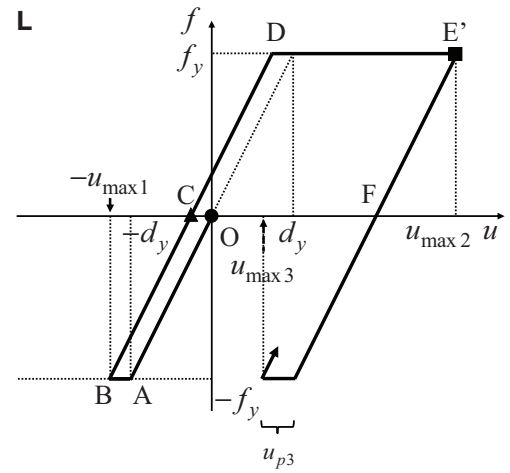

FIGURE 2 | Prediction of maximum elastic-plastic deformation under triple impulse based on energy approach: (A-C) Case 1: elastic response, (D-F) Case 2: plastic response after the third impulse,
(G-I) Case 3: plastic response after the second impulse, (J-L) Case 4: plastic response after the first impulse ( $\bullet$ : first impulse, $\Delta$ : second impulse, $\square$ : third impulse). 
In comparison with the double impulse, the triple impulse is quite difficult to derive the critical timing in a general case. This is because the timing of three impulses is fixed and there exist many complicated situations. In this paper, a case is treated where the critical timing is defined only before the third impulse. This means that, if the third impulse does not exist, timing gives the maximum value of $u_{\max 2}$.

\section{Case 1}

Figures 2A-C show the maximum deformation after the first impulse, that after the second impulse, and that after the third impulse, respectively, for the elastic case (Case 1) during the whole stage. $u_{\max 1}$ can be obtained from the energy conservation law.

$$
m(0.5 V)^{2} / 2=k u_{\max 1}^{2} / 2
$$

On the other hand, since it can be proved that the critical timing of the second impulse to produce the maximum deformation $u_{\max 2}$ is the time of zero restoring force (the proof similar to the Section "Proof of Critical Timing" in Appendix), $u_{\max 2}$ can be computed from another energy conservation law.

$$
m(0.5 V+V)^{2} / 2=k u_{\max 2}^{2} / 2
$$

In the elastic case, the critical timing of the second impulse is the time of zero restoring force and the velocity $-V$ by the second impulse is added to the velocity $-0.5 \mathrm{~V}$ induced by the first impulse (full recovery at the zero restoring force due to zero damping).

Furthermore, since the timing of the third impulse is the time of zero restoring force, $u_{\max 3}$ can be computed from another energy conservation law.

$$
m(0.5 V+V+0.5 V)^{2} / 2=k u_{\max 3}^{2} / 2
$$

As explained above, the critical timing of the third impulse is the time of zero restoring force and the velocity $0.5 \mathrm{~V}$ by the third impulse is added to the velocity $1.5 \mathrm{~V}$ induced by the first and second impulses (full recovery at the zero restoring force due to zero damping).

It should be noted again that the critical timing $t_{0}$ corresponds to the time of zero restoring force in Case 1 (see Proof of Critical Timing in Appendix). As a result, $u_{\max 3}$ becomes the largest deformation among $u_{\max 1}, u_{\max 2}$, and $u_{\max 3}$.

\section{Case 2}

Consider next the case (Case 2) where the model goes into the yielding stage after the third impulse. Figures 2D-F show the schematic response in this case. As in Case $1, u_{\max 1}$ can be obtained from the energy conservation law.

$$
m(0.5 V)^{2} / 2=k u_{\max 1}^{2} / 2
$$

On the other hand, $u_{\max 2}$ can be computed from another energy conservation law.

$$
m(0.5 V+V)^{2} / 2=k u_{\max 2}^{2} / 2
$$

As stated above, the velocity - $V$ by the second impulse is added to the velocity $-0.5 \mathrm{~V}$ induced by the first impulse. Furthermore, $u_{\max 3}$ can be computed from another energy conservation law.

$$
m(0.5 V+V+0.5 V)^{2} / 2=f_{\mathrm{y}} d_{\mathrm{y}} / 2+f_{\mathrm{y}}\left(u_{\max 3}-d_{\mathrm{y}}\right)
$$

As explained above, the velocity $0.5 \mathrm{~V}$ by the third impulse is added to the velocity $1.5 \mathrm{~V}$ induced by the first and second impulses. It should be noted that the critical timing $t_{0}$ corresponds to the time of zero restoring force also in Case 2.

\section{Case 3}

Consider next the case (Case 3) where the model goes into the yielding stage after the second impulse. Figures 2G-I show the schematic response in this case. $u_{\max }$ can be obtained from the energy conservation law.

$$
m(0.5 V)^{2} / 2=k u_{\max 1}^{2} / 2
$$

As in Case 2, the critical timing of the second impulse is the time of zero restoring force. Although a more complicated discussion is needed to show this critical timing depending on the timing of the third impulse, it is omitted here. Case 3-1 and Case 3-2 (Figure 3) should be considered in Case 3. In Case 3-1, the timing of the third impulse is in the second unloading stage (Figures 2I and 3A).

\section{Case 3-1}

In this case (Case 3-1), $u_{\max 2}$ can be computed from another energy conservation law.

$$
m(0.5 V+V)^{2} / 2=f_{\mathrm{y}} d_{\mathrm{y}} / 2+f_{\mathrm{y}}\left(u_{\max 2}-d_{\mathrm{y}}\right)
$$

Then, $u_{\max 2}$ can be expressed as

$$
u_{\max 2}=d_{\mathrm{y}}+m\left\{(1.5 V)^{2}-\left(\omega_{1} d_{\mathrm{y}}\right)^{2}\right\} /\left(2 f_{\mathrm{y}}\right)
$$

On the other hand, $u_{\max 3}$ can be computed from another energy conservation law.

$$
m\left(v_{\mathrm{E}^{\prime}}-0.5 V\right)^{2} / 2+k \Delta u_{\mathrm{E}^{\prime} \mathrm{F}} / 2=f_{\mathrm{y}} d_{\mathrm{y}} / 2+f_{\mathrm{y}} u_{\mathrm{p} 3}
$$

where $\nu_{\mathrm{E}^{\prime}}(<0)$ is the velocity at the time of third impulse (point $E^{\prime}$ ) and $\Delta u_{\mathrm{E}^{\prime} \mathrm{F}}=u_{\mathrm{E}^{\prime}}-u_{\mathrm{p} 2}\left(u_{\mathrm{E}^{\prime}}(>0)\right.$ : deformation at $\left.E^{\prime}\right) . u_{\mathrm{p} 2}$ is characterized by $u_{\mathrm{p} 2}=u_{\max 2}-d_{\mathrm{y}}$ and $u_{\mathrm{p} 3}$ satisfies $u_{\max 2}+u_{\max 3}=2 d_{\mathrm{y}}+u_{\mathrm{p} 3}$. $\nu_{\mathrm{E}^{\prime}}$ and $u_{\mathrm{E}^{\prime}}$ are characterized by Eqs 12 and 13 by solving the equation of motion.

$$
\begin{gathered}
v_{\mathrm{E}^{\prime}}=-\omega_{1} d_{\mathrm{y}} \sin \omega_{1} t_{\mathrm{EE}^{\prime}} \\
u_{\mathrm{E}^{\prime}}=d_{\mathrm{y}} \cos \omega_{1} t_{\mathrm{EE}^{\prime}}+u_{\mathrm{p}^{2}}= \\
d_{\mathrm{y}} \cos \omega_{1} t_{\mathrm{EE}^{\prime}}+m\left\{(1.5 V)^{2}\right. \\
\left.-\left(\omega_{1} d_{\mathrm{y}}\right)^{2}\right\} /\left(2 f_{\mathrm{y}}\right)
\end{gathered}
$$

In these equations, $t_{\mathrm{EE}^{\prime}}=\left(T_{1} / 2\right)-\left(t_{\mathrm{CD}}+t_{\mathrm{DE}}\right)$ is the time interval between the first yielding termination point $(E)$ and the third impulse (point $\left.E^{\prime}\right), t_{\mathrm{CD}}=\left\{\operatorname{Sin}^{-1}\left(2 \omega_{1} d_{y} / 3 V\right)\right\} / \omega_{1}$ is the time interval between the time of the second impulse and the time of the first yielding initiation (after the second impulse), and $t_{\mathrm{DE}}=m \sqrt{\left(9 V^{2} / 4\right)-\left(\omega_{1} d_{\mathrm{y}}\right)^{2}} / f_{\mathrm{y}}$ is the time interval between the time of the first yielding initiation (after the second impulse) and the time of the second unloading initiation. $t_{\mathrm{CD}}$ and $t_{\mathrm{DE}}$ are computed by solving the equations of motion and substituting the transition conditions (yielding and unloading conditions). In other words, $u_{\max 3}$ can be obtained from

$$
\begin{aligned}
m\left(v_{\mathrm{E}^{\prime}}-0.5 V\right)^{2} / 2+k \Delta u_{\mathrm{E}^{\prime} \mathrm{F}} / 2= & f_{\mathrm{y}} d_{\mathrm{y}} / 2 \\
& +f_{\mathrm{y}}\left(u_{\max 2}+u_{\max 3}-2 d_{\mathrm{y}}\right)
\end{aligned}
$$



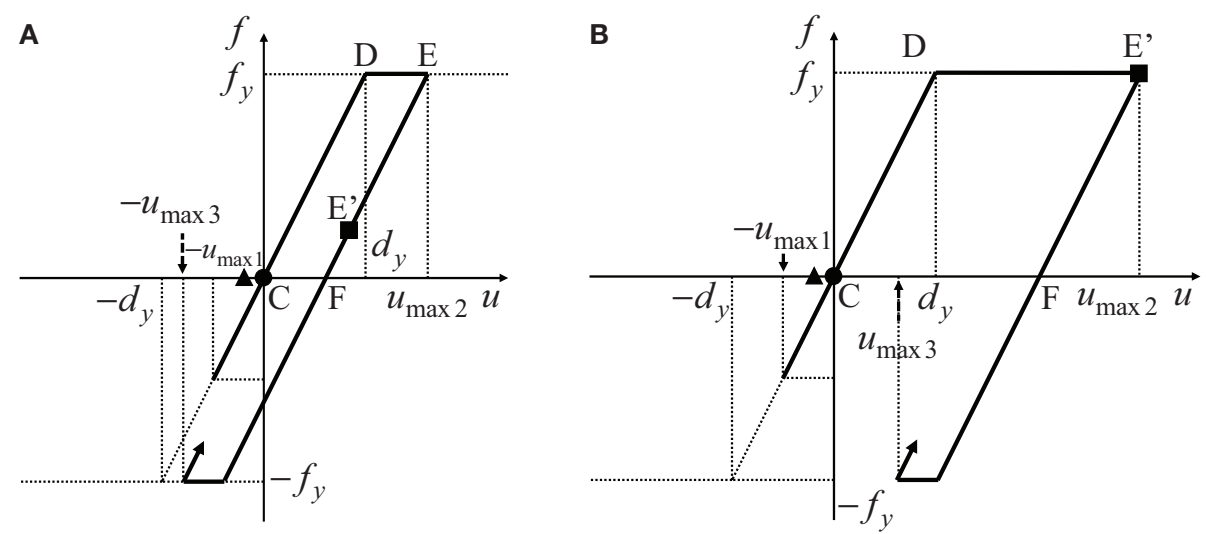

FIGURE 3 | Two different cases in Case 3: (A) Case 3-1, (B) Case 3-2 (•: first impulse, $\Delta$ : second impulse, $\square$ : third impulse)

Then, $u_{\max 3}$ can be expressed as

$$
u_{\max 3}=d_{\mathrm{y}}+m\left\{\left(v_{\mathrm{E}^{\prime}}{ }^{2}-v_{\mathrm{E}^{\prime}} V-2 V^{2}\right)+\left(\omega_{1} \Delta u_{\mathrm{E}^{\prime} \mathrm{F}}\right)^{2}\right\} /\left(2 f_{\mathrm{y}}\right)
$$

If the maximum deformation after the third impulse (corresponding to $u_{\max 3}$ ) is positive, $u_{\mathrm{p} 3}$ is characterized by $u_{\max 2}-u_{\max 3}=2 d_{\mathrm{y}}+u_{\mathrm{p} 3}$. In this case, $u_{\max 3}$ can be computed from another energy conservation law.

$$
\begin{aligned}
m\left(v_{\mathrm{E}^{\prime}}-0.5 V\right)^{2} / 2+k \Delta u_{\mathrm{E}^{\prime} \mathrm{F}} / 2= & f_{\mathrm{y}} d_{\mathrm{y}} / 2 \\
& +f_{\mathrm{y}}\left(u_{\max 2}-u_{\max 3}-2 d_{\mathrm{y}}\right)
\end{aligned}
$$

Then, $u_{\max 3}$ can be expressed by

$$
u_{\max 3}=-d_{\mathrm{y}}-m\left\{\left(v_{\mathrm{E}^{\prime}}{ }^{2}-v_{\mathrm{E}^{\prime}} V-2 V^{2}\right)+\left(\omega_{1} \Delta u_{\mathrm{E}^{\prime} \mathrm{F}}\right)^{2}\right\} /\left(2 f_{\mathrm{y}}\right)
$$

\section{Case 3-2}

In Case 3-2, the timing of the third impulse is in the yielding stage (Figure 3B). In this case (Case 3-2), $u_{\max 2}$ is the deformation at the time of the third impulse $\left(u_{\mathrm{E}^{\prime}}\right) \mathcal{U}_{\mathrm{E}^{\prime}}$ can be computed by solving the equation of motion and can be expressed by Eq. 15 .

$$
u_{\mathrm{E}^{\prime}}=-\left(f_{\mathrm{y}} / 2 m\right) t_{\mathrm{DE}^{\prime}}{ }^{2}+\sqrt{\left(9 V^{2} / 4\right)-\left(\omega_{1} d_{\mathrm{y}}\right)^{2}} t_{\mathrm{DE}^{\prime}}+d_{\mathrm{y}}
$$

In this case, $u_{\max 2}$ is given by

$$
u_{\max 2}=u_{\mathrm{E}^{\prime}}
$$

On the other hand, $u_{\max 3}$ can be computed from another energy conservation law.

$$
m\left(v_{\mathrm{E}^{\prime}}-0.5 V\right)^{2} / 2+f_{\mathrm{y}} d_{\mathrm{y}} / 2=f_{\mathrm{y}} d_{\mathrm{y}} / 2+f_{\mathrm{y}} u_{\mathrm{p} 3}
$$

where $\nu_{\mathrm{E}^{\prime}}$ is the velocity at the third impulse and $u_{\mathrm{p} 3}$ is characterized by $u_{\max 2}-u_{\max 3}=2 d_{\mathrm{y}}+u_{\mathrm{p} 3}$. $\nu_{\mathrm{E}^{\prime}}$ is characterized by Eq. 18 by solving the equation of motion.

$$
v_{\mathrm{E}^{\prime}}=-\left(f_{\mathrm{y}} / m\right) t_{\mathrm{DE}^{\prime}}+\sqrt{\left(9 V^{2} / 4\right)-\left(\omega_{1} d_{\mathrm{y}}\right)^{2}}
$$

In these equations, $t_{\mathrm{DE}^{\prime}}=\left(T_{1} / 2\right)-t_{\mathrm{CD}}$ is the time interval between the first yielding initiation and the third impulse and $t_{\mathrm{CD}}=\left\{\operatorname{Sin}^{-1}\left(2 \omega_{1} d_{y} /(3 V)\right)\right\} / \omega_{1}$ is the time interval between the time of the second impulse (zero restoring force) and the time of the first yielding initiation (after the second impulse). $t_{\mathrm{CD}}$ is computed by solving the equation of motion and substituting the transition conditions (yielding and unloading conditions). In other words, $u_{\max 3}$ can be obtained from

$$
\begin{aligned}
& m\left(v_{\mathrm{E}^{\prime}}-0.5 V\right)^{2} / 2+f_{\mathrm{y}} d_{\mathrm{y}} / 2 \\
& \quad=f_{\mathrm{y}} d_{\mathrm{y}} / 2+f_{\mathrm{y}}\left(u_{\max 2}-u_{\max 3}-2 d_{\mathrm{y}}\right)
\end{aligned}
$$

Then, $u_{\max 3}$ can be expressed by

$$
u_{\max 3}=-2 d_{\mathrm{y}}+u_{\mathrm{E}^{\prime}}-m\left(v_{\mathrm{E}^{\prime}}-0.5 \mathrm{~V}\right)^{2} /\left(2 f_{\mathrm{y}}\right)
$$

\section{Case 4}

Consider finally the case (Case 4) where the model goes into the yielding stage even after the first impulse. Figures 2J-L show the schematic response in this case. $u_{\max }$ can be obtained from the energy conservation law.

$$
m(0.5 \mathrm{~V})^{2} / 2=f_{\mathrm{y}} d_{\mathrm{y}} / 2+f_{\mathrm{y}}\left(u_{\max 1}-d_{\mathrm{y}}\right)
$$

In this case (Case 4$), u_{\max }$ is the deformation at the third impulse $\left(u_{\mathrm{E}^{\prime}}\right) . u_{\mathrm{E}^{\prime}}$ can be computed by solving the equation of motion and $u_{\mathrm{E}^{\prime}}$ can be obtained from Eq. 21 .

$$
\begin{aligned}
u_{\mathrm{E}^{\prime}}= & -\left(f_{\mathrm{y}} / 2 m\right) t_{\mathrm{DE}^{\prime}}^{2}+\sqrt{V^{2}+2 \omega_{1} d_{\mathrm{y}} V} t_{\mathrm{DE}^{\prime}}+d_{\mathrm{y}} \\
& -m\left\{\left(V^{2} / 4\right)-\left(\omega_{1} d_{\mathrm{y}}\right)^{2}\right\} /\left(2 f_{\mathrm{y}}\right)
\end{aligned}
$$

In this case, $u_{\max 2}$ is given by

$$
u_{\max 2}=u_{\mathrm{E}^{\prime}}
$$

On the other hand, $u_{\max 3}$ can be computed from another energy conservation law.

$$
m\left(v_{\mathrm{E}^{\prime}}-0.5 V\right)^{2} / 2+f_{\mathrm{y}} d_{\mathrm{y}} / 2=f_{\mathrm{y}} d_{\mathrm{y}} / 2+f_{\mathrm{y}} u_{\mathrm{p} 3}
$$

where $\nu_{\mathrm{E}^{\prime}}$ is the velocity at the third impulse and $u_{\mathrm{p} 3}$ is characterized by $u_{\max 2}-u_{\max 3}=2 d_{\mathrm{y}}+u_{\mathrm{p} 3}$. $\nu_{\mathrm{E}^{\prime}}$ is characterized by Eq. 24 by solving the equation of motion.

$$
v_{\mathrm{E}^{\prime}}=-\left(f_{\mathrm{y}} / m\right) t_{\mathrm{DE}^{\prime}}+\sqrt{V^{2}+2 \omega_{1} d_{\mathrm{y}} V}
$$

In these equations, $t_{\mathrm{DE}^{\prime}}=t_{0}-t_{\mathrm{CD}}=\left(t_{\mathrm{OA}}+t_{\mathrm{AB}}+t_{\mathrm{BC}}\right)-t_{\mathrm{CD}}$ is the time interval between the second yielding initiation 
and the third impulse and $t_{0}$ is the time interval between the time of the first impulse and the time of the second impulse. $t_{\mathrm{OA}}=\left\{\operatorname{Sin}^{-1}\left(2 \omega_{1} d_{\mathrm{y}} / V\right)\right\} / \omega_{1}$ is the time interval between the time of the first impulse and the time of the first yielding initiation, $t_{\mathrm{AB}}=m \sqrt{\left(V^{2} / 4\right)-\left(\omega_{1} d_{\mathrm{y}}\right)^{2}} / f_{\mathrm{y}}$ is the time interval between the time of the first yielding initiation and the time of the first unloading initiation, $t_{\mathrm{BC}}=T_{1} / 4$ is the time interval between the time of the first unloading initiation and the time of the second impulse and $t_{\mathrm{CD}}=\left\{\operatorname{Sin}^{-1}\left(\omega_{1} d_{\mathrm{y}} /\left(\omega_{1} d_{\mathrm{y}}+V\right)\right)\right\} / \omega_{1}$ is the time interval between the time of the second impulse and the time of the second yielding initiation. $t_{\mathrm{OA}}, t_{\mathrm{AB}}$, and $t_{\mathrm{CD}}$, are computed by solving the equation of motion and substituting the transition conditions (yielding and unloading conditions). In other words, $u_{\max 3}$ can be obtained from

$$
\begin{aligned}
m\left(v_{\mathrm{E}^{\prime}}-0.5 V\right)^{2} / 2+f_{\mathrm{y}} d_{\mathrm{y}} / 2= & f_{\mathrm{y}} d_{\mathrm{y}} / 2 \\
& +f_{\mathrm{y}}\left(u_{\max 2}-u_{\max 3}-2 d_{\mathrm{y}}\right)
\end{aligned}
$$

Then, $\mathcal{u}_{\max 3}$ can be expressed by

$$
u_{\max 3}=-2 d_{\mathrm{y}}+u_{\mathrm{E}^{\prime}}-m\left(v_{\mathrm{E}^{\prime}}-0.5 V\right)^{2} /\left(2 f_{\mathrm{y}}\right)
$$

Figure 4 shows the plot of $u_{\max } / d_{\mathrm{y}}=\max \left(u_{\max 1} / d_{\mathrm{y}}, u_{\max 2} / d_{\mathrm{y}}\right.$, $\left.u_{\max 3} / d_{\mathrm{y}}\right)$ with respect to the input level. $2 V_{\mathrm{y}}$ is the input level at which the maximum deformation after the first impulse just attain the yield deformation $d_{\mathrm{y}}$. Here, $V_{\mathrm{y}}$ is expressed by $V_{\mathrm{y}}=\omega_{1} d_{\mathrm{y}}$. As stated before, there are four cases (Case 1-4).

Case 1: elastic response during all response stages $\left(u_{\max 3}\right.$ is the largest).

Case 2: yielding after the third impulse ( $u_{\max 3}$ is the largest).

Case 3: yielding after the second impulse $\left(u_{\max 2}\right.$ or $u_{\max 3}$ is the largest).

Case 4: yielding after the first impulse ( $u_{\max 2}$ is the largest).

In Case 1 and $2, u_{\max }$ is the largest. On the other hand, in Case 3, $u_{\max 2}$ or $u_{\max 3}$ is the largest and in Case $4, u_{\max 2}$ is the largest.

As observed in Figure 3, the timing of the third impulse sometimes decreases $u_{\max 2}$. It may be useful to assume the timing of the third impulse at the zero restoring force in the unloading process as shown in Figure 5. In Case 1 and 2, this assumption is valid (see Figures 2C,F). Figure 6 presents the corresponding figure in which the timing of the third impulse is the time of zero restoring force after the attainment of $u_{\max 2}$ (in the process of the second unloading). In Figure 6, four cases (Case $1^{*}$, Case $2^{*}$, Case $3^{\star}$, Case $4^{*}$ ) are introduced corresponding to the previously defined four cases. Case $1^{\star}$ and Case $2^{\star}$ are Case 1 and Case 2 themselves. It can be understood, because the timing of the third impulse defined as the same interval between the first and second impulses decreases $u_{\max 2}, u_{\max } / d_{\mathrm{y}}$ in Case 4 in Figure 4 becomes smaller than that in Figure 6. However, it is noteworthy that $u_{\max } / d_{\mathrm{y}}$ in Figure 6 can be a good upper bound of that in Figure 4 and $u_{\max } / d_{\mathrm{y}}\left(u_{\max 2} / d_{\mathrm{y}}\right)$ to any other timing $t_{0}$ (except zero restoring force) does not become larger than that in Figure 6 (see Proof of Critical Timing and Upper Bound of Response Ductility via Relaxation of Timing of Third Impulse in Appendix).

Figure 7 presents the normalized timing $t_{0} / T_{1}\left(T_{1}=2 \pi / \omega_{1}\right)$ of the second impulse with respect to the input level. As stated before,

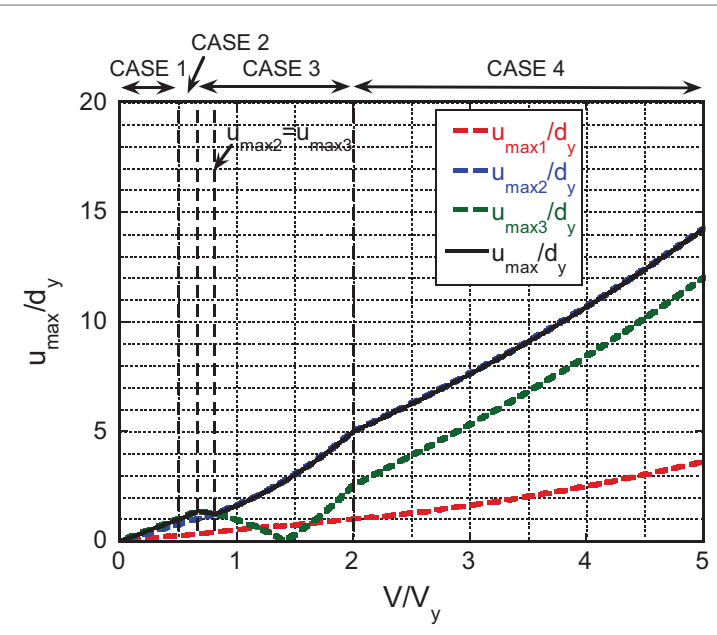

FIGURE 4 | Maximum normalized elastic-plastic deformation under triple impulse with respect to input level.

this timing coincides with the time of zero restoring force after the first unloading (see Figure 2). It can be observed that the timing is delayed as the input level increases. It seems noteworthy to state again that only critical response giving the maximum value of $u_{\max 2} / d_{\mathrm{y}}$ (in case of the timing of the third impulse after the second unloading) is sought by the proposed method and the critical resonant frequency is obtained automatically for the increasing input level of the triple impulse. One of the original points in this paper is the tracking of the critical elastic-plastic response.

\section{Accuracy Check by Time-History Response Analysis Subjected to the Corresponding Three Wavelets of Sinusoidal Waves}

In order to investigate the accuracy of using the triple impulse as a substitute of the corresponding three wavelets of sinusoidal waves (representative of the forward-directivity input), the time-history response analysis of the elastic-plastic SDOF model under the three wavelets of sinusoidal waves has been conducted.

In the evaluation procedure, it is important to adjust the input level of the triple impulse and the corresponding three wavelets of sinusoidal waves based on the equivalence of the Fourier amplitude. Figure $\mathbf{8}$ shows one example for the input level $V / V_{\mathrm{y}}=3$. Figures 9A,B illustrate the comparison of the ground displacement and velocity between the triple impulse and the corresponding three wavelets of sinusoidal waves for the input level $V / V_{\mathrm{y}}=3$. Only in Figures 8 and $\mathbf{9 A , B}, \omega_{1}=2 \pi(\mathrm{rad} / \mathrm{s})\left(T_{1}=1.0 \mathrm{~s}\right)$ and $d_{\mathrm{y}}=0.16(\mathrm{~m})$ are used.

Figure 10 presents the comparison of the ductility (maximum normalized deformation) of the elastic-plastic structure under the triple impulse and the corresponding three wavelets of sinusoidal waves with respect to the input level. It can be seen that the triple impulse provides a good substitute of the three wavelets of sinusoidal waves in the evaluation of the maximum deformation if the maximum Fourier amplitude is adjusted appropriately. 

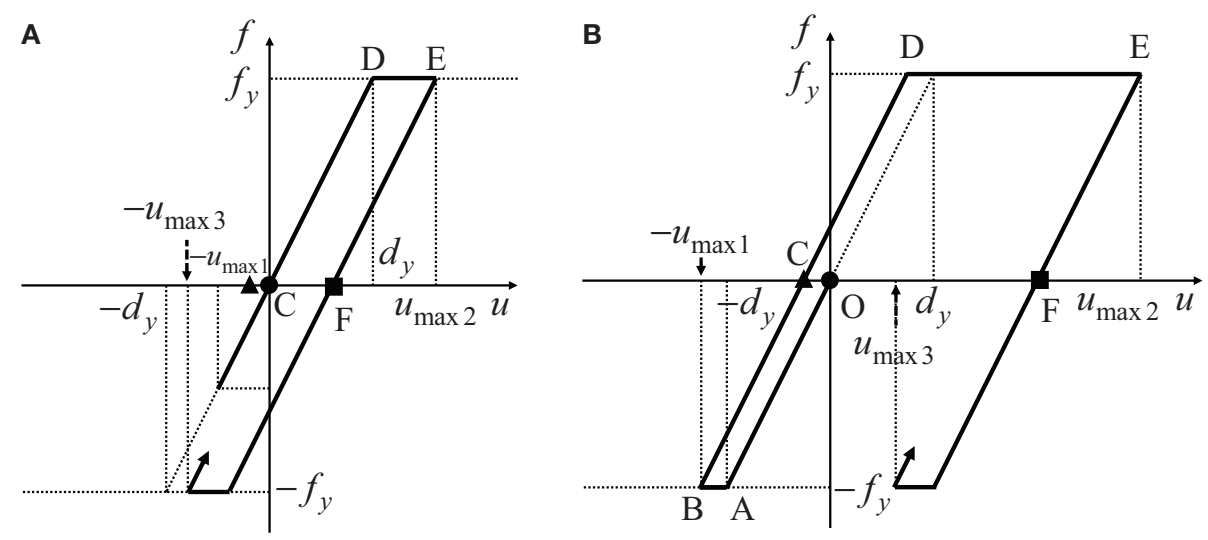

FIGURE 5 | Modified version of timing of the third impulse: (A) Case 3, (B) Case 4 (•: first impulse, $\Delta$ : second impulse, $\square$ : third impulse)

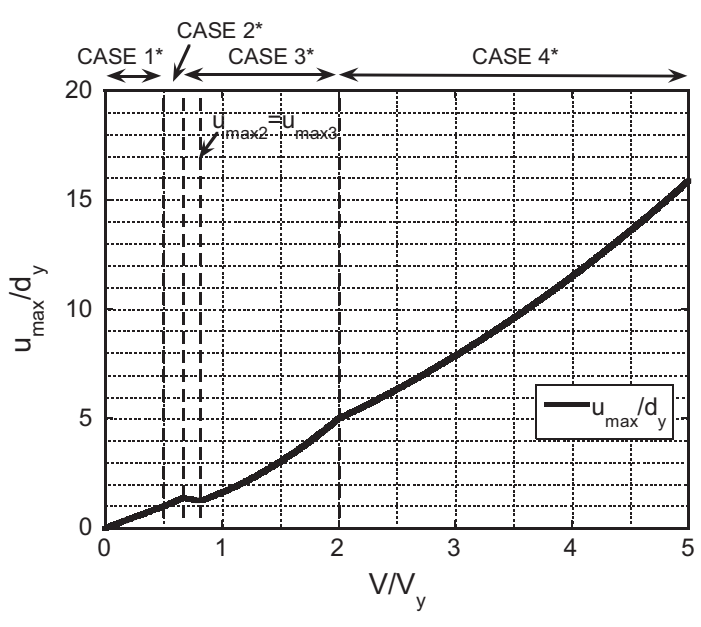

FIGURE 6 | Maximum normalized elastic-plastic deformation under triple impulse with respect to input level (timing of the third impulse: zero restoring force).

Figure 11 shows the comparison of the earthquake input energies by the triple impulse and the corresponding three wavelets of sinusoidal waves. An extremely accurate correspondence can be observed. This supports the validity of the triple impulse as a substitute of the forward-directivity near-fault ground motion.

Figure 12 illustrates the comparison of response time histories (normalized deformation and restoring force) under triple impulse and those under the corresponding three wavelets of sinusoidal waves. The parameters $\omega_{1}=2 \pi(\mathrm{rad} / \mathrm{s})\left(T_{1}=1.0 \mathrm{~s}\right)$, $d_{\mathrm{y}}=0.16(\mathrm{~m})$ are used here. While a rather good correspondence can be seen in general, the amplitude of deformation after the third impulse exhibits a slight difference resulting from the difference in timing of the third impulse. At the same time, a difference in phase can be observed both in the deformation and restoring force. This may also result from the difference in timing of the third impulse. The difference in the amount of energy input at the third impulse seems influence the later response.

Figure 13 presents the comparison of the restoring force characteristic under the triple impulse and that under the

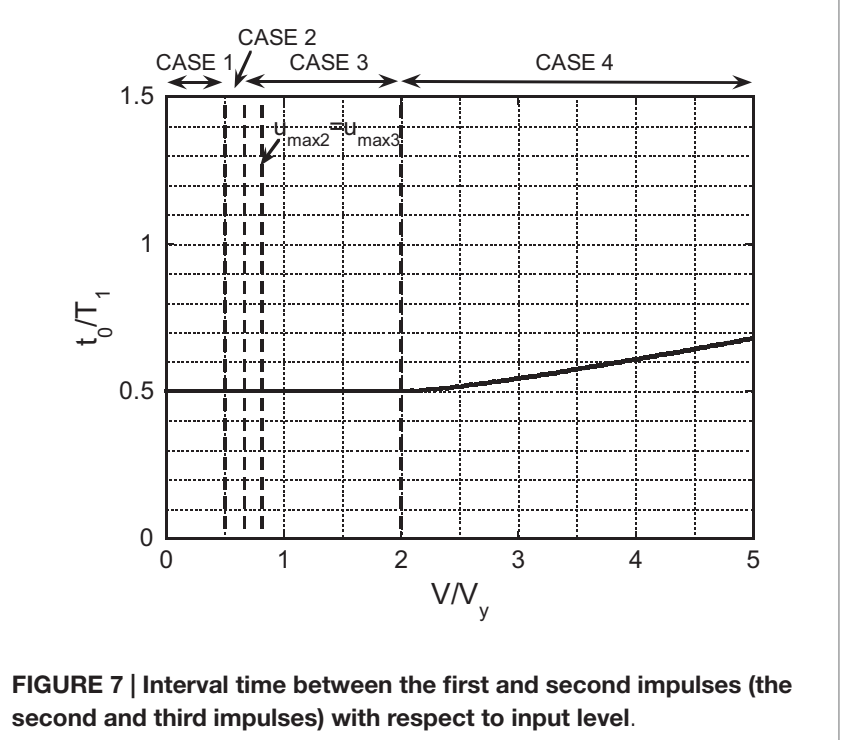

corresponding three wavelets of sinusoidal wave. The parameters $\omega_{1}=2 \pi(\mathrm{rad} / \mathrm{s})\left(T_{1}=1.0 \mathrm{~s}\right), d_{\mathrm{y}}=0.16(\mathrm{~m})$ are also used here. As seen in Figure 12, while the maximum deformations after the first and second impulses exhibit a rather good correspondence, the deformation response after the third impulse exhibits an unnegligible difference. However, since the deformation response after the third impulse does not affect the maximum deformation in an overall time range, this difference may not be significant.

\section{Design of Stiffness and Strength for Specified Velocity and Period of Forward- Directivity Near-Fault Ground Motion Input and Response Ductility}

As in the case of the double impulse as a substitute of the nearfault fling-step input, it may be meaningful to present a flowchart for design of stiffness and strength for the specified velocity and period of the near-fault forward-directivity input and response ductility. This design concept is based on the philosophy that, 


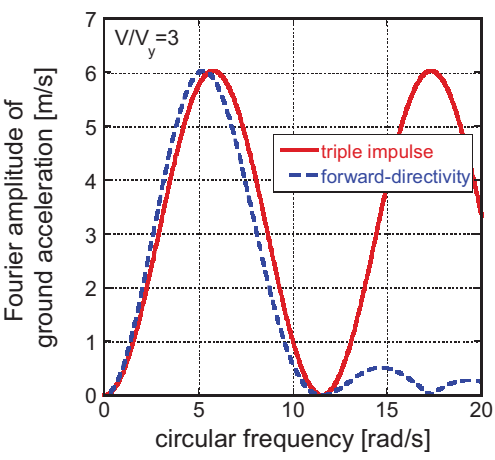

FIGURE 8 | Adjustment of input level of triple impulse and the corresponding three wavelets of sinusoidal waves based on Fourier amplitude equivalence.
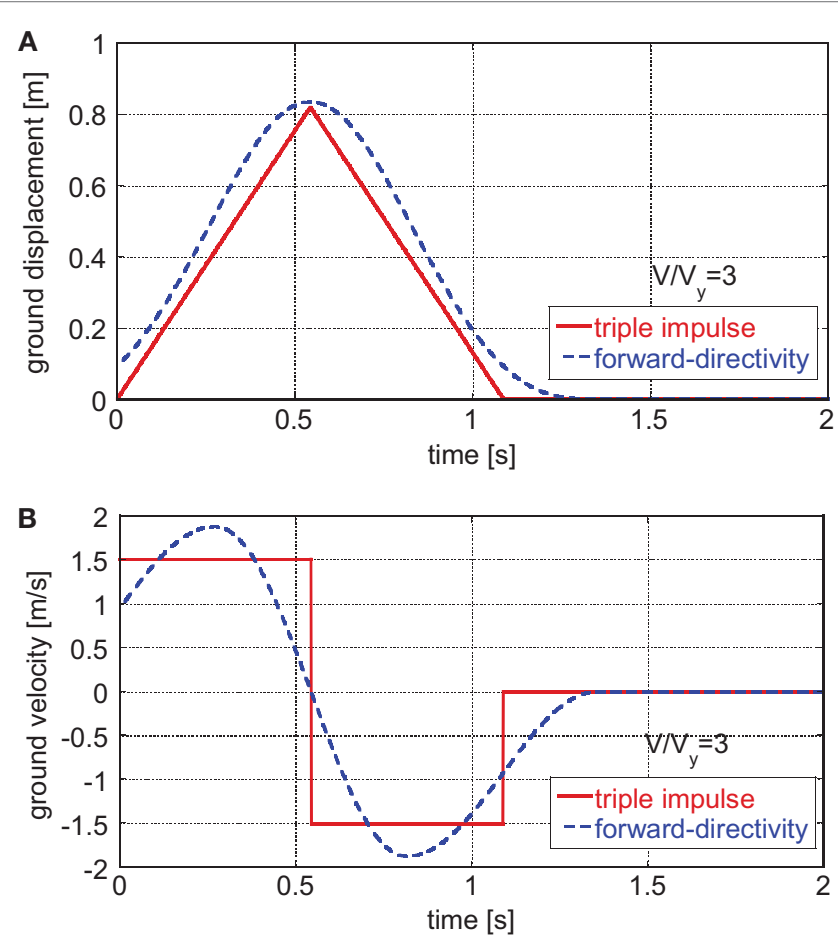

FIGURE 9 | Comparison of ground displacement and velocity between triple impulse and the corresponding three wavelets of sinusoidal waves: (A) displacement, (B) velocity.

if we focus on the worst case of resonance, the safety for other non-resonant cases is guaranteed (Takewaki, 2002). This fact will be explained in the following section.

Since Figures 4 and 7 are non-dimensional ones, they can be used for such design. Figure $\mathbf{1 4}$ shows the flowchart for design of stiffness and strength. One example can be drawn as follows:

[Specified conditions] $V=2.00(\mathrm{~m} / \mathrm{s}), t_{0}=0.500(\mathrm{~s}), u_{\max } / d_{\mathrm{y}}=4.00$, $m=4.00 \times 10^{6}(\mathrm{~kg})$

[Design results] $/ V_{\mathrm{y}}=1.70, \quad V_{\mathrm{y}}=1.18(\mathrm{~m} / \mathrm{s}), \quad T_{1}=1.00(\mathrm{~s})$, $d_{\mathrm{y}}=0.188(\mathrm{~m}), k=1.58 \times 10^{8}(\mathrm{~N} / \mathrm{m}), f_{\mathrm{y}}=2.97 \times 10^{7}(\mathrm{~N})$

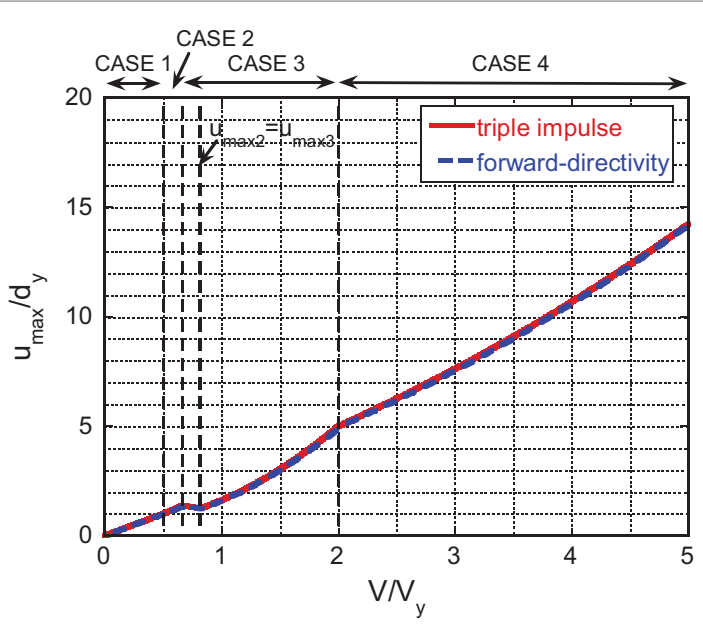

FIGURE 10 | Comparison of ductility of elastic-plastic structure under triple impulse and the corresponding three wavelets of sinusoidal waves.

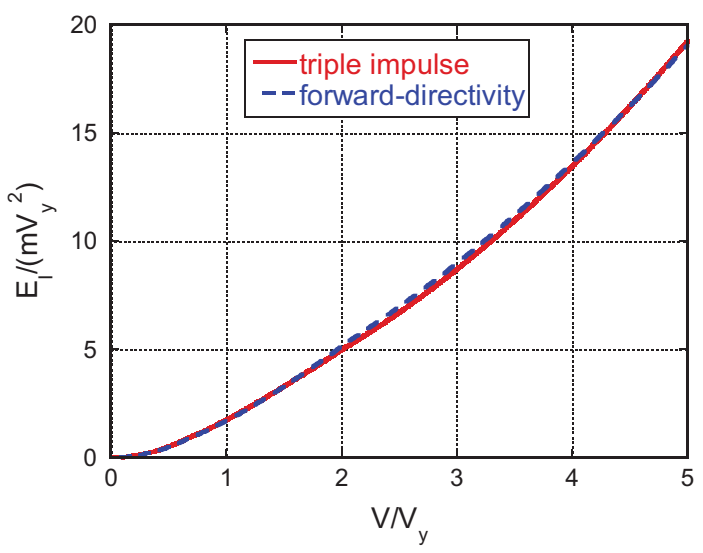

FIGURE 11 | Comparison of earthquake input energies by triple impulse and the corresponding three wavelets of sinusoidal waves.

From Figure 4, $V / V_{\mathrm{y}}=1.70$ can be obtained for the specified ductility $u_{\text {max }} / d_{\mathrm{y}}=4.0$. Then, $V_{\mathrm{y}}=1.18(\mathrm{~m} / \mathrm{s})$ is derived from the specified condition $V=2.00(\mathrm{~m} / \mathrm{s})$ and $V / V_{\mathrm{y}}=1.70$. In the next step, $T_{1}=1.00(\mathrm{~s})$ is found from Figure 7 for $V / V_{\mathrm{y}}=1.70$ and $t_{0}=0.5(\mathrm{~s})$. In this model, $d_{\mathrm{y}}=0.188(\mathrm{~m})$ is determined from $V_{\mathrm{y}}=\omega_{1} d_{\mathrm{y}}$ and $T_{1}=\left(2 \pi / \omega_{1}\right)=1.00(\mathrm{~s})$. Finally, $k=1.58 \times 10^{8}(\mathrm{~N} / \mathrm{m})$ is obtained from $k=\omega_{1}^{2} m$ and $f_{\mathrm{y}}=2.97 \times 10^{7}(\mathrm{~N})$ is derived by $f_{\mathrm{y}}=k d_{\mathrm{y}}$.

\section{Approximate Prediction of Response Ductility for Specified Design of Stiffness and Strength and Specified Velocity and Period of Near-Fault Ground Motion Input}

Until Section "Accuracy Check by Time-History Response Analysis Subjected to the Corresponding Three Wavelets of Sinusoidal Waves," only the critical set of velocity and period of 

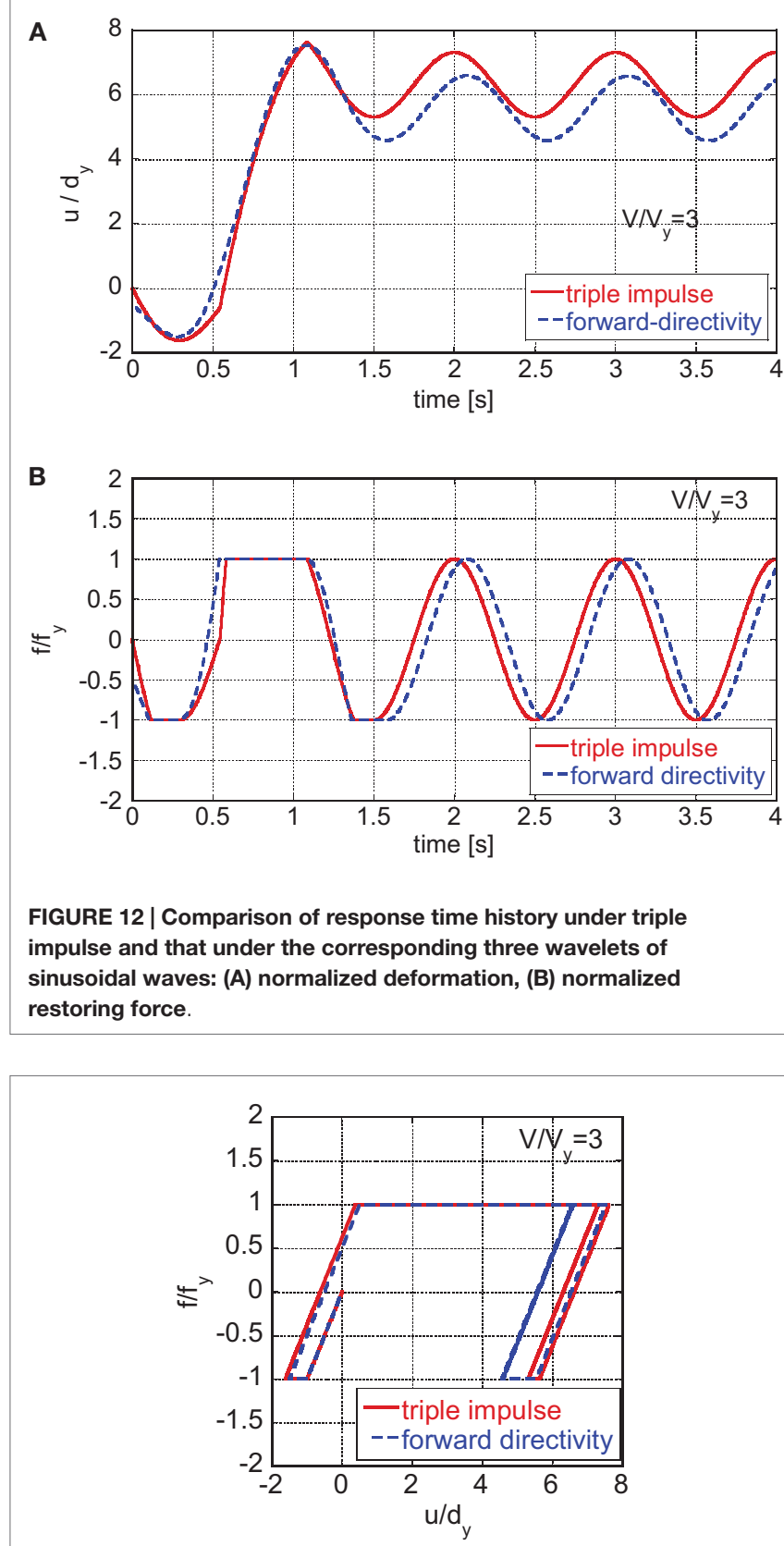

FIGURE 13 | Comparison of restoring force characteristic under triple impulse and that under the corresponding three wavelets of sinusoidal waves.

near-fault ground motion input and the corresponding critical response have been treated for a specified design of stiffness and strength. On the other hand, in Section "Design of Stiffness and Strength for Specified Velocity and Period of Forward-Directivity Near-Fault Ground Motion Input and Response Ductility," the design flowchart of stiffness and strength for the specified velocity and period of the near-fault ground motion input and specified response ductility has been presented. In this section, an approximate prediction method of response ductility for specified design of stiffness and strength and specified velocity
Specify $V, t_{0}, m(V$ is determined from velocity amplitude of three wavelets of sinusoidal waves based on equivalence of Fourier amplitude of input acceleration)

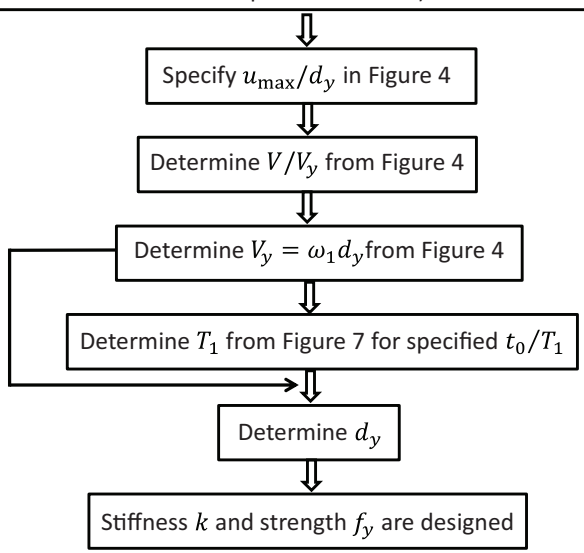

FIGURE 14 | Flowchart for design of stiffness and strength

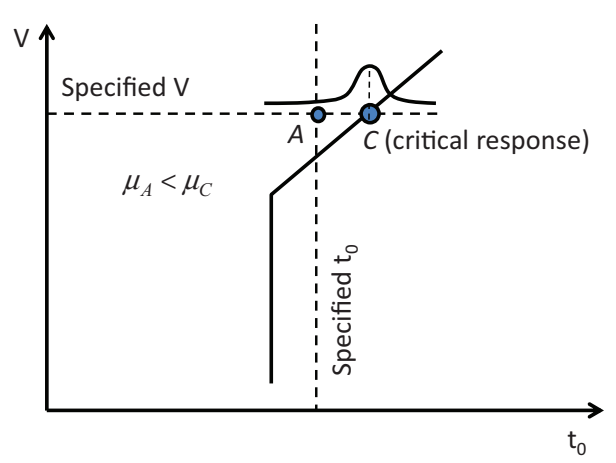

FIGURE 15 | Schematic diagram of approximate prediction method of response ductility for specified design of stiffness and strength and specified velocity and period of near-fault ground motion input.

and period of near-fault ground motion input is explained. If a more exact response is desired then the response analysis for an arbitrary timing of impulses and an arbitrary input level can be done.

Figure 15 shows a schematic diagram of the approximate prediction method (only prediction of upper bound) of response ductility $\mu=u_{\max } / d_{\mathrm{y}}$ for a specified design of stiffness and strength and a specified velocity and period of near-fault ground motion input using the corresponding critical response. Generally, the specified set of velocity and period of near-fault ground motion input is not the critical set for a given structure. In such case, consider the critical set (point $C$ ) of velocity and period of input corresponding to the specified set of velocity. Let $\mu_{\mathrm{A}}$ and $\mu_{\mathrm{C}}$ denote the response ductilities corresponding to point A and C. From the Section "Proof of Critical Timing" in Appendix, $\mu_{\mathrm{A}}<\mu_{\mathrm{C}}$ can be drawn directly. This enables an approximate prediction of response ductility (only upper bound) for a specified design of stiffness and strength and a specified velocity and period of near-fault ground motion input. 


\section{Conclusion}

The conclusions may be summarized as follows:

(1) The triple impulse input has been introduced as a simplified version of the forward-directivity near-fault ground motion and a closed-form solution of the critical elastic-plastic response of a structure by this triple impulse input has been derived.

(2) It has been shown that, since only the free-vibration appears under such triple impulse input, the energy approach plays an important role in the derivation of the closed-form solution of a complicated elastic-plastic response. In other words, the energy approach enables the derivation of the maximum elastic-plastic seismic response. In this process, the input of impulse is expressed by the instantaneous change of velocity of the structural mass. The maximum elastic-plastic response after impulse can be obtained by equating the initial kinetic energy computed by the initial velocity to the sum of hysteretic and elastic strain energies. It has been shown that the maximum inelastic deformation can occur after either the second or third impulse depending on the input level.

(3) The validity and accuracy of the proposed theory have been investigated through the comparison with the response analysis result to the corresponding three wavelets of sinusoidal input as a representative of the forward-directivity near-fault ground motion. It has been made clear that, if the level of the triple impulse is adjusted so that its maximum Fourier amplitude coincides with that of the corresponding three wavelets of sinusoidal input, the maximum elastic-plastic deformation to the triple impulse exhibits a good correspondence with that to the three wavelets of sinusoidal wave.

(4) While the resonant equivalent frequency has to be computed for a specified input level by changing the excitation frequency in a parametric manner in dealing with the sinusoidal input, no iteration is required in the proposed method for the triple impulse. This is because the resonant equivalent frequency (resonance can be proved by using energy investigation) can be obtained directly without the repetitive procedure

\section{References}

Abbas, A. M., and Manohar, C. S. (2002). Investigations into critical earthquake load models within deterministic and probabilistic frameworks. Earthq. Eng. Struct. Dyn. 31, 813-832. doi:10.1002/eqe.124.abs

Alavi, B., and Krawinkler, H. (2004). Behaviour of moment resisting frame structures subjected to near-fault ground motions. Earthq. Eng. Struct. Dyn. 33, 687-706. doi:10.1002/eqe.370

Bertero, V. V., Mahin, S. A., and Herrera, R. A. (1978). Aseismic design implications of near-fault San Fernando earthquake records. Earthq. Eng. Struct. Dyn. 6, 31-42. doi:10.1002/eqe.4290060105

Bray, J. D., and Rodriguez-Marek, A. (2004). Characterization of forwarddirectivity ground motions in the near-fault region. Soil Dyn. Earthq. Eng. 24, 815-828. doi:10.1016/j.soildyn.2004.05.001

Caughey, T. K. (1960). Sinusoidal excitation of a system with bilinear hysteresis. J. Appl. Mech. 27, 640-643. doi:10.1115/1.3644077

Drenick, R. F. (1970). Model-free design of aseismic structures. J. Eng. Mech. Div. 96, 483-493. (the timing of the second impulse can be characterized as the time with zero restoring force). In the triple impulse, the analysis can be conducted without the input frequency (timing of impulses) before the second impulse. It should be noted that, while a simple and clear concept of critical input was defined in the case of double impulse (Kojima and Takewaki, 2015b), the criticality can be used only before the third impulse in the present triple impulse. This is because the timing of the third impulse, determined already for the first and second impulses, decreases the maximum deformation $u_{\max 2}$ after the second impulse and may increase the maximum deformation $u_{\max 3}$ after the third impulse.

(5) Only critical response (upper bound) is captured by the proposed method and the critical resonant frequency can be obtained automatically for the increasing input level of the triple impulse. Once the frequency and amplitude of the critical triple impulse are computed, the corresponding three wavelets of sinusoidal motion as a representative of the forward-directivity motion can be identified.

(6) A flowchart for design of stiffness and strength for the specified velocity and period of the near-fault ground motion input and response ductility has been proposed using the newly derived non-dimensional relations among response ductility, input velocity, and input period. It has been demonstrated that this flowchart can provide a useful result for such design.

(7) An approximate prediction method of response ductility (only prediction of upper bound) using the corresponding critical response can be developed for a specified design of stiffness and strength and a specified velocity and period of near-fault ground motion input.

\section{Acknowledgments}

Part of the present work is supported by the Grant-in-Aid for Scientific Research of Japan Society for the Promotion of Science (No. 24246095, No. 15H04079) and the 2013-MEXT-Supported Program for the Strategic Research Foundation at Private Universities in Japan (No. S1312006). This support is greatly appreciated.

Hall, J. F., Heaton, T. H., Halling, M. W., and Wald, D. J. (1995). Near-source ground motion and its effects on flexible buildings. Earthq. Spectra 11, 569-605. doi:10.1193/1.1585828

Hayden, C. P., Bray, J. D., and Abrahamson, N. A. (2014). Selection of near-fault pulse motions. J. Geotech. Geoenviron. Eng. 140:04014030. doi:10.1061/(ASCE) GT.1943-5606.0001129

Kalkan, E., and Kunnath, S. K. (2006). Effects of fling step and forward directivity on seismic response of buildings. Earthq. Spectra 22, 367-390. doi:10.1193/1.2192560

Kalkan, E., and Kunnath, S. K. (2007). Effective cyclic energy as a measure of seismic demand. J. Earthq. Eng. 11, 725-751. doi:10.1080/13632460601033827

Khaloo, A. R., Khosravil, H., and Hamidi Jamnani, H. (2015). Nonlinear interstory drift contours for idealized forward directivity pulses using "Modified Fish-Bone” models. Adv. Struct. Eng. 18, 603-627. doi:10.1260/1369-4332. 18.5.603

Kojima, K., Fujita, K., and Takewaki, I. (2015a). Critical double impulse input and bound of earthquake input energy to building structure. Front. Built Environ. 1:5. doi:10.3389/fbuil.2015.00005 
Kojima, K., and Takewaki, I. (2015b). Critical earthquake response of elastic-plastic structures under near-fault ground motions (Part 1: Fling-step input). Front. Built Environ. 1:12. doi:10.3389/fbuil.2015.00012

Liu, C.-S. (2000). The steady loops of SDOF perfectly elastoplastic structures under sinusoidal loadings. J. Mar. Sci. Technol. 8, 50-60.

Mavroeidis, G. P., Dong, G., and Papageorgiou, A. S. (2004). Near-fault ground motions, and the response of elastic and inelastic single-degree-freedom (SDOF) systems. Earthq. Eng. Struct. Dyn. 33, 1023-1049. doi:10.1002/eqe.391

Mavroeidis, G. P., and Papageorgiou, A. S. (2003). A mathematical representation of near-fault ground motions. Bull. Seismol. Soc. Am. 93, 1099-1131. doi:10.1785/0120020100

Moustafa, A., Ueno, K., and Takewaki, I. (2010). Critical earthquake loads for SDOF inelastic structures considering evolution of seismic waves. Earthq. Struct. 1, 147-162. doi:10.12989/eas.2010.1.2.147

Mukhopadhyay, S., and Gupta, V. K. (2013a). Directivity pulses in near-fault ground motions - I: identification, extraction and modeling. Soil Dyn. Earthq. Eng. 50, 1-15. doi:10.1016/j.soildyn.2013.02.017

Mukhopadhyay, S., and Gupta, V. K. (2013b). Directivity pulses in near-fault ground motions - II: estimation of pulse parameters. Soil Dyn. Earthq. Eng. 50, 38-52. doi:10.1016/j.soildyn.2013.02.019

Rupakhety, R., and Sigbjörnsson, R. (2011). Can simple pulses adequately represent near-fault ground motions? J. Earthq. Eng. 15, 1260-1272. doi:10.1080/136324 69.2011 .565863

Sasani, M., and Bertero, V. V. (2000). "Importance of severe pulse-type ground motions in performance-based engineering: historical and critical review," in Proceedings of the Twelfth World Conference on Earthquake Engineering (Auckland).

Takewaki, I. (2002). Robust building stiffness design for variable critical excitations. J. Struct. Eng. ASCE 128, 1565-1574. doi:10.1061/(ASCE)0733-9445 (2002)128:12(1565)

Takewaki, I. (2004). Bound of earthquake input energy. J. Struct. Eng. ASCE 130, 1289-1297. doi:10.1061/(ASCE)0733-9445(2004)130:9(1289)
Takewaki, I. (2007). Critical Excitation Methods in Earthquake Engineering, 2nd Edn. Oxford: Elsevier, 2013.

Takewaki, I., Moustafa, A., and Fujita, K. (2012). Improving the Earthquake Resilience of Buildings: The Worst Case Approach. London: Springer.

Takewaki, I., and Tsujimoto, H. (2011). Scaling of design earthquake ground motions for tall buildings based on drift and input energy demands. Earthq. Struct. 2, 171-187. doi:10.12989/eas.2011.2.2.171

Vafaei, D., and Eskandari, R. (2015). Seismic response of mega buckling-restrained braces subjected to fling-step and forward-directivity near-fault ground motions. Struct. Des. Tall Spec. Build. 24, 672-686. doi:10.1002/tal.1205

Xu, Z., Agrawal, A. K., He, W.-L., and Tan, P. (2007). Performance of passive energy dissipation systems during near-field ground motion type pulses. Eng. Struct. 29, 224-236. doi:10.1016/j.engstruct.2006.04.020

Yamamoto, K., Fujita, K., and Takewaki, I. (2011). Instantaneous earthquake input energy and sensitivity in base-isolated building. Struct. Des. Tall Spec. Build. 20, 631-648. doi:10.1002/tal.539

Yang, D., and Zhou, J. (2014). A stochastic model and synthesis for near-fault impulsive ground motions. Earthq. Eng. Struct. Dyn. 44, 243-264. doi:10.1002/eqe.2468

Zhai, C., Chang, Z., Li, S., Chen, Z.-Q., and Xie, L. (2013). Quantitative identification of near-fault pulse-like ground motions based on energy. Bull. Seismol. Soc. Am. 103, 2591-2603. doi:10.1785/0120120320

Conflict of Interest Statement: The authors declare that the research was conducted in the absence of any commercial or financial relationships that could be construed as a potential conflict of interest.

Copyright (C) 2015 Kojima and Takewaki. This is an open-access article distributed under the terms of the Creative Commons Attribution License (CC BY). The use, distribution or reproduction in other forums is permitted, provided the original author(s) or licensor are credited and that the original publication in this journal is cited, in accordance with accepted academic practice. No use, distribution or reproduction is permitted which does not comply with these terms. 


\section{Appendix}

\section{Proof of Critical Timing}

In comparison with the double impulse, the triple impulse is quite difficult to derive the critical timing in a general case. This is because the timing of three impulses is fixed and there exist many complicated situations. In this paper, a case is treated where the critical timing is defined only before the third impulse. This means that, if the third impulse does not exist, timing gives the maximum value of $u_{\max 2}$. The following explanation is the same as in the previous paper for the double impulse.

Consider the critical timing of the second impulse. Let $v_{c}$ denote the velocity of the mass passing the zero restoring force (zero elastic strain energy) after the first unloading and $\nu^{*}, u^{*}$ denote the velocity and the elastic deformation component at an arbitrary point between the first unloading and the second yielding. Since the first unloading starts from the state with zero velocity and the elastic strain energy $f_{\mathrm{y}} d_{\mathrm{y}} / 2$, the relation $m v_{\mathrm{c}}^{2} / 2=f_{\mathrm{y}} d_{\mathrm{y}} / 2$ holds. From the energy conservation law between the first unloading and the second yielding, the relation $m v^{*} / 2+k u^{*} / 2=f_{y} d_{y} / 2$ holds. Consider the second impulse at the same time of the state of $\nu^{*}, u^{*}$. The total mechanical energy can be expressed by $m\left(v^{*}+V\right)^{2} / 2+k u^{* 2} / 2$. Since the relation $m\left(\nu^{*}+V\right)^{2} / 2+k u^{* 2} / 2=m v^{* 2} / 2+k u^{* 2} / 2+m \nu^{*} V+$ $m V^{2} / 2=f_{\mathrm{y}} d_{\mathrm{y}} / 2+m v^{*} V+m V^{2} / 2$ holds and the maximum deformation after the second yielding is caused by the maximum total mechanical energy, the maximum velocity $\nu^{\star}$ causes the maximum deformation after the second yielding. This timing is the zero restoring force after the first unloading. This completes the proof.

\section{Upper Bound of Response Ductility via Relaxation of Timing of Third Impulse}

The case is treated here where the third impulse acts at the timing of zero restoring force in the second unloading process. It can be shown that this case provides the larger maximum deformation $u_{\max 2}$ than the case treated before (the same timing between the first and second impulses).

Consider the case where the model goes into the yielding stage even after the first impulse. The case where the model goes into the yielding stage after the second impulse (elastic after the first impulse) can be explained in almost the same manner. Figure 5B shows the schematic response in this case. $u_{\max }$ can be obtained from the energy conservation law.

$$
m(0.5 V)^{2} / 2=f_{\mathrm{y}} d_{\mathrm{y}} / 2+f_{\mathrm{y}} u_{\mathrm{p} 1}=f_{\mathrm{y}} d_{\mathrm{y}} / 2+f_{\mathrm{y}}\left(u_{\max 1}-d_{\mathrm{y}}\right)
$$

On the other hand, $u_{\max 2}$ can be computed from another energy conservation law.

$$
m\left(v_{\mathrm{c}}+V\right)^{2} / 2=f_{\mathrm{y}} d_{\mathrm{y}} / 2+f_{\mathrm{y}} u_{\mathrm{p} 2}
$$

where $v_{\mathrm{c}}$ is characterized by $m v_{\mathrm{c}}^{2} / 2=f_{\mathrm{y}} d_{\mathrm{y}} / 2$ and $u_{\mathrm{p} 2}$ is characterized by $u_{\max 2}+\left(u_{\max 1}-d_{\mathrm{y}}\right)=d_{\mathrm{y}}+u_{\mathrm{p} 2}$. In other words, $u_{\max 2}$ can be obtained from

$$
m\left(v_{\mathrm{c}}+V\right)^{2} / 2=f_{\mathrm{y}} d_{\mathrm{y}} / 2+f_{\mathrm{y}}\left(u_{\max 1}+u_{\max 2}-2 d_{\mathrm{y}}\right)
$$

Furthermore, $u_{\max 3}$ can be computed from another energy conservation law.

$$
m\left(v_{\mathrm{c}}+0.5 V\right)^{2} / 2=f_{\mathrm{y}} d_{\mathrm{y}} / 2+f_{\mathrm{y}} u_{\mathrm{p} 3}
$$

where $u_{\mathrm{p} 3}$ is characterized by $-u_{\max 3}+\left(u_{\max 2}-d_{\mathrm{y}}\right)=d_{\mathrm{y}}+u_{\mathrm{p} 3}$. In other words, $u_{\max 3}$ can be obtained from

$$
m\left(v_{\mathrm{c}}+0.5 V\right)^{2} / 2=f_{\mathrm{y}} d_{\mathrm{y}} / 2+f_{\mathrm{y}}\left(u_{\max 2}-u_{\max 3}-2 d_{\mathrm{y}}\right)
$$

